Case Report

\title{
Successful Treatment with Corticosteroids in an 11-Year-Old Patient with Crohn's Disease and Myopericarditis-Case Report
}

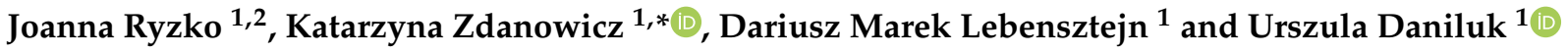 \\ 1 Department of Pediatrics, Gastroenterology, Hepatology, Nutrition and Allergology, Medical University of \\ Bialystok, Waszyngtona St. 17, 15-274 Białystok, Poland; joannaryzko@gmail.com (J.R.); \\ lebensztejn@hoga.pl (D.M.L.); urszula.daniluk@umb.edu.pl (U.D.) \\ 2 Department of Gastroenterology, Hepatology, Feeding Disorders and Pediatrics, The Children's Memorial \\ Health Institute, 04-730 Warsaw, Poland \\ * Correspondence: kazdanowicz@gmail.com; Tel.: +48-857450710
}

check for

updates

Citation: Ryzko, J.; Zdanowicz, K.;

Lebensztejn, D.M.; Daniluk, U.

Successful Treatment with

Corticosteroids in an 11-Year-Old

Patient with Crohn's Disease and

Myopericarditis-Case Report.

Pediatr. Rep. 2022, 14, 26-31.

https://doi.org/10.3390/

pediatric14010005

Academic Editor:

Carl Philip Kaplan

Received: 25 November 2021

Accepted: 7 January 2022

Published: 11 January 2022

Publisher's Note: MDPI stays neutral with regard to jurisdictional claims in published maps and institutional affiliations.

Copyright: () 2022 by the authors. Licensee MDPI, Basel, Switzerland. This article is an open access article distributed under the terms and conditions of the Creative Commons Attribution (CC BY) license (https:// creativecommons.org/licenses/by/ $4.0 /)$.

\begin{abstract}
Extraintestinal manifestations (EIMs) are observed in 15-20\% of patients with inflammatory bowel disease (IBD). One of the rare EIMs is myocarditis, the incidence of which is estimated at around $1 \%$. The main cause of myocarditis is a viral infection. Other causes include autoimmune diseases and drug complications (sulfasalazine, mesalazine). We present the case of an 11-year-old girl with Crohn's disease (CD) with EIMs, manifested as hip joint inflammation and erythema nodosum. At the same time, the symptoms of myopericarditis appeared with changes in electrocardiogram (ECG), echocardiography and high troponin I concentration. Therapy with corticosteroids resulted in the resolution of skin lesions and cardiological symptoms. Systemic connective tissue diseases, viral and bacterial infections were excluded in the differential diagnosis. The suspicion of mesalazine-induced EIMs was also ruled out as the symptoms resolved despite continued therapy with mesalazine. No further recurrences of myopericarditis were observed.
\end{abstract}

Keywords: Crohn's disease; extraintestinal manifestations; myocarditis; children

\section{Introduction}

Crohn's disease (CD) is a chronic inflammatory bowel disease (IBD) of unknown etiology, characterized by periods of remission and exacerbation. The pathogenesis of the disease has not been fully understood, and so far genetic, environmental and immunological factors have been mentioned as causes of inflammation.

Myocarditis is an inflammatory process in which myocyte necrosis can occur. The most common causes of myocarditis in children are viral infections (mainly enteroviruses), followed by bacterial infections, drugs, and autoimmune disease. The prevalence of myocarditis concerns about $1 \%$ of hospitalized children and about $8-21 \%$ of sudden cardiac deaths in children and young adults [1,2].

Myocarditis and myopericarditis may also be a rare extraintestinal manifestation (EIM) of IBD. In most cases it is a side effect of IBD treatment, mainly with sulfasalazine or mesalazine [3-10]. It is estimated that less than $1 \%$ of children and adults with IBD present cardiovascular symptoms.

\section{Case Report}

An 11-year-old girl was admitted to the hospital due to pain in the area of the left buttock and hip joint accompanied by a fever lasting several days (up to $39^{\circ} \mathrm{C}$ ). In addition, the girl reported the occurrence of loose stools for 3-4 weeks and weight loss (about $3 \mathrm{~kg}$ ). Family history revealed asthma and celiac disease in the patient's sister. Laboratory tests showed an increase in the concentration of the C-reactive protein (CRP) - $49.46 \mathrm{mg} / \mathrm{L}$, low levels of iron $(18 \mu \mathrm{g} / \mathrm{dL})$ and vitamin D3 $(12 \mathrm{ng} / \mathrm{mL})$, high fecal calprotectin (FC) $(1100 \mu \mathrm{g} / \mathrm{g})$ and a positive fecal occult blood test. Imaging examination (X-ray, ultrasound) 
and orthopedic consultation allowed to exclude hip arthritis. An antibiotic (amoxicillin with clavulanic acid), anti-inflammatory drugs and vitamin D supplementation were recommended.

After next 2 weeks, the girl was admitted to our department because of bloody stools and persistent pain in the left hip. Physical examination revealed a lean body posture (BMI 3-10 percentiles), palpable abdominal pain in the lower abdomen, and persistent pain in left hip. Laboratory tests showed increased inflammatory markers such as CRP $(60.07 \mathrm{mg} / \mathrm{L})$, white blood count $\left(\mathrm{WBC}, 11.90 \times 10^{3} / \mu \mathrm{L}\right)$, erythrocyte sedimentation rate $(\mathrm{ESR}, 64 \mathrm{~mm} / \mathrm{h})$ and a high FC value $(2482.7 \mu \mathrm{g} / \mathrm{g})$. Ultrasound examination of the abdominal cavity revealed a slightly thickened cecum wall $(3.7 \mathrm{~mm})$. During hospitalization, bacterial (including tuberculosis), viral (cytomegalovirus, rotavirus, adenonovirus) infections, parasitic infestation and celiac disease were excluded. Gastroduodenoscopic examination revealed scattered aphtous erosions in the antrum of the stomach and erosions covered with fibrin on the anterior and posterior wall of the duodenal bulb. Ileocolonoscopy revealed numerous aphthous erosions in the large intestine and single ones in the tip of the ileum. MR enteroclysis scans showed a thickened wall of the distal ileum. Histopathological examination of the ileum and colon specimens showed the inflammatory lesions suggesting CD. Based on clinical, endoscopic and imaging examinations, CD was diagnosed (Paris classification: A1c, L2, B1 G1). Disease activity based on the PCDAI (Pediatric Crohn's Disease Activity Index) was rated at 45 points (moderate activity). Exclusive enteral nutrition was started as the first-line therapy for CD. After disease remission was induced, an immunosuppressant drug (azathioprine) and an anti-inflammatory drug (mesalamine) were used to maintain remission.

Two weeks after the discharge from the hospital, the patient was re-admitted due to deterioration of her general condition with fever, chest pain and erythema nodosum. Using physical examination, tachycardia (HR 140/min), nodular lesions on the extensor of the lower straight parts and underweight $(\mathrm{BMI}<3)$ were detected. Laboratory tests showed a significant increase in inflammatory markers (CRP $234.84 \mathrm{mg} / \mathrm{L}, \mathrm{WBC} 17.1 \times 10^{3} / \mu \mathrm{L}$, ESR $88 \mathrm{~mm} / \mathrm{hr})$, a low iron level $(8 \mu \mathrm{g} / \mathrm{dL})$ and high FC $(2497.7 \mu \mathrm{g} / \mathrm{g})$. Due to the reported chest pain, the concentration of troponin was assessed, showing its elevation $(92 \mathrm{ng} / \mathrm{L}$ [normal value: $0-19 \mathrm{ng} / \mathrm{L}$ ], Figure 1).



Figure 1. Troponin I values during myocarditis treatment.

The electrocardiogram (ECG) recording was normal. Broad-spectrum antibiotic therapy (amikacin, cephtazidim) and antifungal drugs were used in the treatment. Control tests performed on the second day of hospitalization revealed a significant increase in troponin I (13,312 ng/L, Figure 2), a slight increase in CRP compared to the previous day, 
hypoalbuminemia (3.17 g/dL) and increased activity of creatine kinase (CK; $297 \mathrm{IU} / \mathrm{L})$ and creatine kinase-MB (CK-MB; $50 \mathrm{IU} / \mathrm{L})$. The ECG record showed an elevated ST segment in V2-V6 leads (Figure 2).

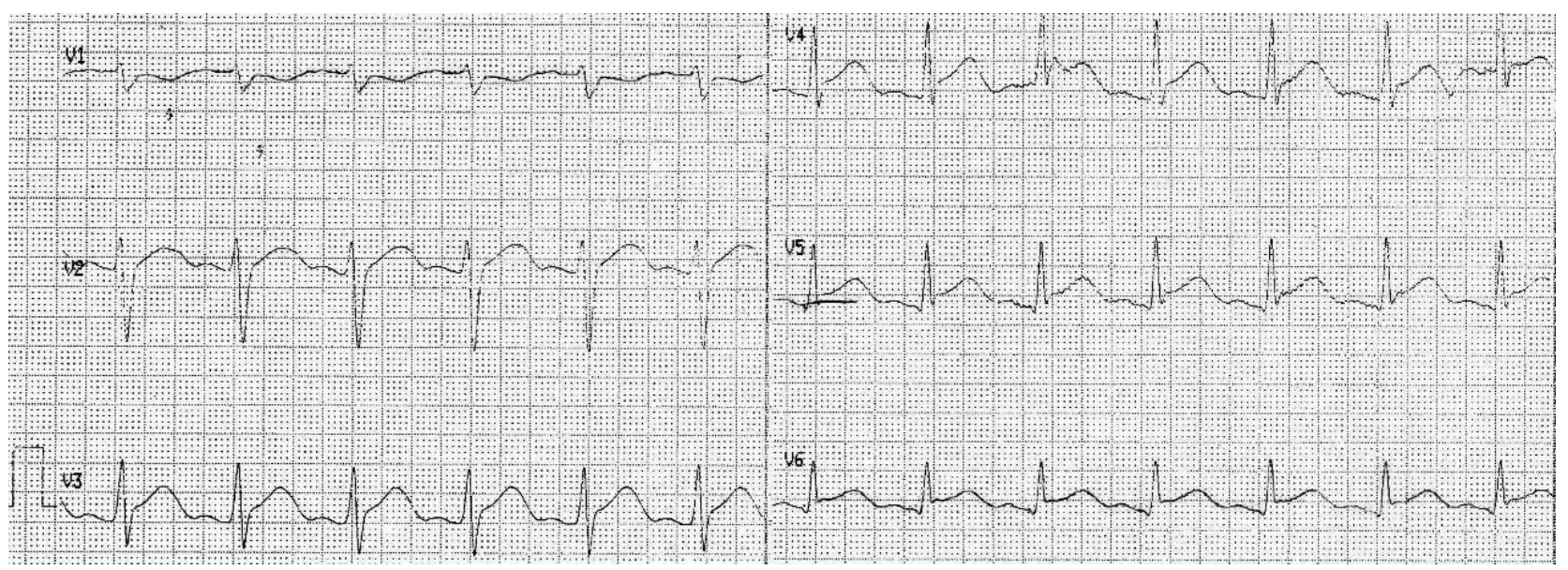

Figure 2. ECG recording on the 3rd day of hospitalization.

Echocardiography (ECHO) examination did not reveal any significant abnormalities. Vancomycin and systemic steroid therapy (methyloprednisolone) were added to the treatment. On the 3rd day of hospitalization, a gradual decrease of troponin I (Figure 1) and CRP (Figure 3) was noted. ST-segment elevation was still observed in all leads of the ECG record, while $\mathrm{ECHO}$ examination revealed the appearance of pericardial effusion with a $5 \mathrm{~mm}$ of pericardial separation in diastole. Hyperkinetic circulation was suspected based on increased cardiac output and a high heart rate. Cardiac magnetic resonance imaging (CMR) was not performed because of technical limitations. Due to tachycardia, no signs of heart failure and the need to prolong diastole, a beta-blocker was included in the treatment (metoprolol $23.75 \mathrm{mg} /$ daily). Viral and bacterial infections (Epstein-Barr virus, Cytomegalovirus, Coxsackie, Parvo-virus B19, Influenza A and B, Streptococcus, Mycoplasma, Yersinia) were excluded in the differential diagnosis of myopericarditis. Serological tests for systemic connective tissue diseases were negative. In subsequent control tests, a systematic improvement in the patient's general condition was observed with a gradual decrease in the level of troponin I and inflammatory markers (Figures 1 and 3). The girl was discharged home with the recommendation to continue steroid therapy with gradual dose reduction. Due to the high resting heart rate (90-110/min), cardiac therapy was extended to 12 months. CD treatment with azathioprine and mesalazine was continued.

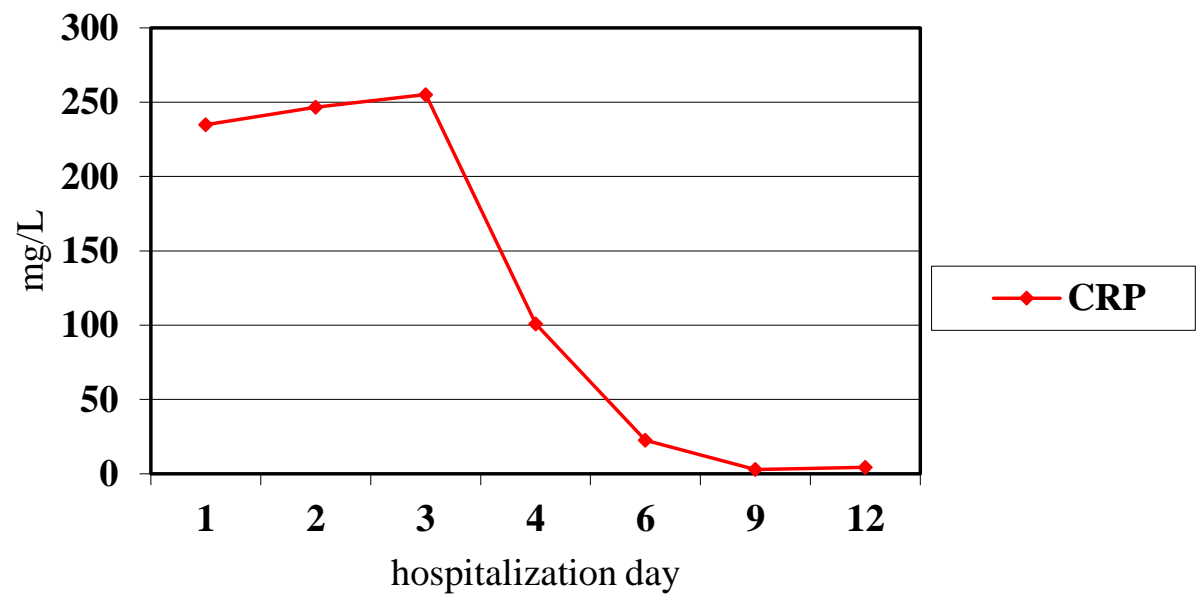

Figure 3. CRP values during observation of myocarditis. 
After 2 years of combination therapy with azathioprine and mesalazine, another exacerbation of $C D$ with loose stools (up to $4-5$ per day), abdominal pain, low-grade fever and pain complaints of elbow and knee joints was observed. Laboratory results showed an increase in inflammatory parameters (ESR $43 \mathrm{~mm} / \mathrm{h}$, platelets $498,000 / \mu \mathrm{L}$ ) and mild anemia ( $\mathrm{Hb} 11 \mathrm{~g} / \mathrm{dL}$ ). FC increased to $2527.5 \mu \mathrm{g} / \mathrm{g}$. The endoscopic examination revealed disseminated mucosal aphthous erosions in the descending part of the duodenum and extensive inflammatory changes along the entire length of the colon, as well as single aphthous erosions in sigmoid and rectum (Paris classification-A1b, L2, B1). The PCDAI score was assessed at 55 points, which corresponds to a severe disease. Taking into account the disease progression, biological treatment with adalimumab was started. Azathioprine treatment was continued. During the 3-year monitoring conducted by cardiologist, no recurrences of myopericarditis or complications after myopericarditis were found.

\section{Discussion}

In the presented case, $\mathrm{CD}$ was diagnosed based on the manifested symptoms (abdominal pain, weight loss, recurrent diarrhea with negative stool cultures), endoscopic findings (inflammatory lesions in the terminal ileum and caecum and stomach), histopathological examination, and the image of MR enteroclysis (thickened wall of the distal ileum). It is worth to notice the gradual progression of the clinical course from nonspecific abdominal pain and diarrhea at the onset of the disease to extraintestinal symptoms of $\mathrm{CD}$ with cardiac involvement [4].

However, cardiac involvement in the course of IBD is very rare. In the literature, which mainly concerns adults, a higher incidence of myocarditis is noted in patients with ulcerative colitis (UC) than CD [11]. The pathomechanism of myocarditis in IBD seems to be more complex and not fully understood [12]. The coexistence of infectious, autoimmune conditions or drug-related complications are considered to be involved in development of miocarditis. In the presented case, the viral background was excluded on the basis of serological tests. There was also no indication for an endomyocardial biopsy according to the guidelines of The American College of Cardiology, the American Heart Association and the European Society of Cardiology [13,14].

Due to rapid improvement after initiation of corticosteroids with concurrent resolution of intestinal and skin lesions and resolution of clinical and biochemical symptoms of myocardial disease, cardiovascular disease should be treated as an EIM of CD, similar to erythema nodosum and hip symptoms in our patient. McGrath-Cadell et al. reported a case of a young women with mobile valvular masses and myocarditis possibly secondary to active $C D$, in which clinical improvement was not achieved despite treatment with broad-spectrum antibiotics. Only after administration of steroids (prednisolone) and anticoagulants the symptoms were finally relieved [15]. However, in another report, acute myopericarditis occurred 2 weeks after the intensification of therapy (prednisone and mesalazine) due to exacerbation of CD. Clinical improvement was achieved after use of colchicine with an increase in the dose of steroid [16]. Additionally, in adult patients with UC complicated by myocarditis, administration of corticosteroids led to symptoms relief [17-19]. The authors of the reported cases proposed the concomitant administration of colchicine to prevent the recurrence of myocarditis [17-19].

Some authors have suggested a link between myocarditis and the use of mesalazine $[17,20]$. Several mechanisms of masalazine toxicity have been proposed, i.e., inhibition of prostaglandin production (inhibition of cyclooxygenase activity), hypersensitivity reactions (cytokines stimulated by eosinophils), cross-reactions of anti-mesalazine antibodies with the cardiac tissue, direct toxic effects of mesalazine on the heart muscle and pericardium, and allergic reactions [18]. In contrast, other authors found no association of mesalazine in the development of myocarditis in IBD patients [12,20,21]. In our case, the relationship between myocarditis and 5-ASA treatment was excluded, because myocarditis did not recur despite continued use of this drug. 
In the two-year follow-up of our patient, no myocarditis was observed despite the progression of Crohn's disease during immunosuppressive treatment requiring the initiation of biological therapy with an anti-TNF $\alpha$ monoclonal antibody. However, the patient requires monitoring of the cardiovascular system, as the literature also includes reports of myocarditis after biological treatment [22,23].

\section{Conclusions}

The reported case concerns the rarely observed coexistence of myocarditis with CD. Systemic steroid therapy in IBD with concomitant myocarditis as an EIM remains the first-line therapy. Due to possible recurrences of myocarditis in the course of IBD, the patient should be under the care of a cardiologist.

Author Contributions: Conceptualization, J.R. and U.D.; methodology, J.R. and K.Z.; software, J.R.; validation, K.Z., U.D. and D.M.L.; formal analysis, J.R. and K.Z.; investigation, U.D.; resources, D.M.L.; data curation, K.Z.; writing—original draft preparation, J.R. and K.Z; writing-review and editing, D.M.L. and U.D.; visualization, J.R. and K.Z.; supervision, D.M.L. and U.D.; project administration, U.D.; funding acquisition, U.D. All authors have read and agreed to the published version of the manuscript.

Funding: The APC was funded by Medical University of Bialystok, Poland, grant number SUB/1/DN/ 21/004/1143.

Institutional Review Board Statement: The study was conducted according to the guidelines of the Declaration of Helsinki, and approved by the Ethics Committee of Medical University of Bialystok (R-I-002/402/2018).

Informed Consent Statement: Informed consent was obtained from patient involved in the study.

Data Availability Statement: Data available via email.

Conflicts of Interest: The authors declare no conflict of interest.

\section{References}

1. Kindermann, I.; Barth, C.; Mahfoud, F.; Ukena, C.; Lenski, M.; Yilmaz, A.; Klingel, K.; Kandolf, R.; Sechtem, U.; Cooper, L.T.; et al. Update on myocarditis. J. Am. Coll. Cardiol. 2012, 59, 779-792. [CrossRef]

2. Magnani, J.W.; Dec, G.W. Myocarditis current trends in diagnosis and treatment. Circulation 2006, 113, 876-890. [CrossRef]

3. Jose, F.A.; Heyman, M.B. Extraintestinal Manifestations of Inflammatory Bowel Disease. J. Pediatr. Gastroenterol. Nutr. 2008, 46, 124-133. [CrossRef]

4. Frid, C.; Bjarke, B.; Eriksson, M. Myocarditis in Children with Inflammatory Bowel Disease. J. Pediatr. Gastroenterol. Nutr. 1986, 5, 964-965. [CrossRef]

5. Patwardhan, R.V.; Heilpern, R.J.; Brewster, A.C.; Darrah, J.J. Pleuropericarditis: An Extraintestinal Complication of Inflammatory Bowel Disease. Arch. Intern. Med. 1983, 143, 94-96. [CrossRef]

6. Agnholt, J.O.R.; Sørensen, H.T.; Rasmussen, S.N.; Gøtzsche, C.O.; Halkier, P.; Srensen, H.T.; Gtzsche, C.-O. Cardiac Hypersensitivity to 5-Aminosalicylic Acid. Lancet 1989, 333, 1135. [CrossRef]

7. Gujral, N.; Friedenberg, F.; Friedenberg, J.; Gabriel, G.; Kotler, M.; Levine, G. Pleuropericarditis related to the use of mesalamine. Dig. Dis. Sci. 1996, 41, 624-626. [CrossRef]

8. Galvao Braga, C.; Martins, J.; Arantes, C.; Ramos, V.; Vieira, C.; Salgado, A.; Magalhães, S.; Correia, A. Mesalamine-induced myocarditis following diagnosis of Crohn's disease: A case report. Rev. Port. Cardiol. 2013, 32, 717-720. [CrossRef]

9. Nair, A.G.; Cross, R.R. Mesalamine-induced myopericarditis in a paediatric patient with Crohn's disease. Cardiol. Young 2015, 25, 783-786. [CrossRef]

10. Liu, Y.; Ye, J.; Zhu, J.; Chen, W.; Sun, Y. Myocarditis due to mesalamine treatment in a patient with Crohn's disease in China. Turk. J. Gastroenterol. 2012, 23, 304-306. [CrossRef]

11. Lakatos, L.; Pandur, T.; David, G.; Balogh, Z.; Kuronya, P.; Tollas, A.; Lakatos, P.L. Association of extraintestinal manifestations of inflammatory bowel disease in a province of western Hungary with disease phenotype: Results of 25-year follow-up study. World J. Gastroenterol. 2003, 9, 2300-2307. [CrossRef]

12. Murphy, K.; Waldo, O.; Lohrmann, G.M.; Tazelaar, H.D.; Jokerst, C.E.; Mookadam, F. Eosinophilia and ulcerative colitis associated with eosinophilis myocarditis. Tex. Heart Inst. J. 2017, 44, 219-222. [CrossRef] 
13. Cooper, L.; Baughman, K.L.; Feldman, A.M.; Frustaci, A.; Jessup, M.; Kuhl, U.; Levine, G.N.; Narula, J.; Starling, R.C.; Towbin, J.; et al. The role of endomyocardial biopsy in the management of cardiovascular disease: A Scientific Statement from the American Heart Association, the American College of Cardiology, and the European Society of Cardiology Endorsed by the Heart Failure Society of America and the Heart Failure Association of the European Society of Cardiology. Eur. Heart J. 2007, 28, $3076-3093$. [CrossRef]

14. Leslie, T.; Cooper, M.D., Jr. Myocarditis. N. Engl. J. Med. 2009, 360, 1526-1538.

15. McGrath-Cadell, L.; Bart, N.K.; Lin, L.; Ghaly, S.; Holloway, C.J. Myocarditis in Crohn's disease: A case report. Eur. Heart J. Case Rep. 2020, 4, 1-6. [CrossRef]

16. Kumar, M.; Tandon, V.; Mosebach, C.M.; Lopetegui Lia, N.; Miller, W. Acute Myopericarditis with Crohn's Disease Flare-up. Cureus 2019, 11, e4248. [CrossRef]

17. Freeman, H.J.; Salh, B. Recurrent myopericarditis with extensive ulcerative colitis. Can. J. Cardiol. 2010, 26, 549-550. [CrossRef]

18. Gruenhagen, B.; Alraies, M.C.; Vakil, K.P.; March, S.K. Ulcerative colitis-induced myocarditis. BMJ Case Rep. 2014, 2014, bcr2014204818. [CrossRef]

19. Van Gils, A.J.; van Gijlswijk, S.; Taminiau, J.A.; Marchau, F.; Van De Vijver, E. Recurrent pericarditis as an extra-intestinal manifestation of ulcerative colitis in 14-year old girl. Clin. Case Rep. 2018, 6, 1538-1542. [CrossRef]

20. Okoro, K.U.; Roby, M.D.; Bankole, A.A. Myocarditis secondary to mesalamine- induced cardiotoxicity in a patient with ulcerative colitis. Case Rep. Med. 2018, 2018, 9813893. [CrossRef]

21. Oh, I.S.; Choi, C.H.; Park, J.H.; Kim, J.W.; Cha, B.K.; Do, J.H.; Chang, S.K.; Kwon, G.Y. A case of acute myocarditis as the initial presentation of Crohn's disease. Gut Liver 2012, 6, 512-515. [CrossRef]

22. Reichardt, P.; Dähnert, I.; Tiller, G.; Häusler, H.J. Possibile activation of an intramyocardial inflammatory process (Staphylococcus ureus) after treatment with infliximab in a boy with Crohn disease. Eur. J. Pediatr. 2002, 161, 281-283. [CrossRef]

23. Lezcano-Gort, L.E.; Gomez-Barrado, J.J.; Mogollon-Jimenez, M.V.; Garcipérez-de-Vargas-Díaz, F.J. Hypersensitivity perimyocarditis after the first dose of infliximab. Rev. Esp. Enferm. Dig. 2015, 107, 249. 